\title{
PENERAPAN MODEL PEMBELAJARAN KOOPERATIF TIPE TEAM ASISSTED INDIVIDUALIZATION DENGAN REAL WORLD PROBLEM
}

\author{
Maria Yuliana Kua \\ STKIP Citra Bakti, Nusa Tenggara Timur, Indonesia \\ Email: yulianakua03@gmail.com \\ Ni Wayan Prawita Aryani \\ STKIP Citra Bakti, Nusa Tenggara Timur, Indonesia \\ Email:wayanprawita@gmail.com \\ Josep Marsianus Rewo \\ STKIP Citra Bakti, Nusa Tenggara Timur, Indonesia \\ Email: josmarrewosiu@gmail.com
}

\begin{abstract}
Abstrak
Tujuan penelitian ini adalah untuk mengungkapkan (1) praktis tidaknya penerapan model pembelajaran kooperatif tipe TAI dengan real world problem dalam pembelajaran fisika; (2) tingkat kepraktisan model kooperatif tipe TAI dengan real world problem dalam penerapannya pada proses pembelajaran fisika. Penelitian ini menggunakan 6 langkah pada model pembelajaran kooperatif tipe TAI dengan real world problem. Uji coba dilaksanakan pada kelas X materi momentum dan impuls. Pengambilan sampel menggunakan teknik cluster sampling sehingga diperoleh satu kelas eksperimen yang terdiri dari 34 siswa. Pada saat pembelajaran berlangsung, dilakukan observasi keterlaksanaan setiap fase model pembelajaran kooperatif tipe TAI dengan real world problem. Berdasarkan hasil implementasi model pembelajaran dapat diketahui bahwa (1) model pembelajaran kooperatif tipe TAI dengan real world problem praktis diterapkan dalam pembelajaran fisika (2) model pembelajaran kooperatif tipe TAI dengan real world problem memiliki tingkat kepraktisan yang sangat baik dalam penerapannya pada proses pembelajaran fisika di SMA.
\end{abstract}

Kata kunci: model pembelajaran kooperatif tipe TAI, real world problem

\begin{abstract}
The purpose of this study is to reveal (1) the practicality of cooperative teaching model TAI type with real world problem in physics learning; (2) practical level of cooperative teaching model TAI type with real world problem in its application to physics learning process. This research uses 6 steps in cooperative teaching model TAI type with real world problem. The experiments were carried out in class $\mathrm{X}$ in the learning materials of Momentum and Impulse topics. The research used a cluster random sampling technique to obtain an experimental class consisted of 34 students. At the time of learning took place, observation of the implementation of each phase of cooperative teaching model TAI type with real world problem. Based on the results of the implementation of the teaching model can be seen that (1) cooperative teaching model TAI type with real world problem practical applied in the learning of physics (2) cooperative teaching model TAI type with real world problem has a very good level of practicality in its application in the process of physics learning in high school.
\end{abstract}

Keywords: cooperative teaching model TAI type, real world problem

\section{Pendahuluan}

Pengembangan ilmu pengetahuan secara khusus dilakukan melalui pendidikan formal di bangku sekolah. Dalam keseluruhan proses pendidikan di sekolah, kegiatan pembelajaran merupakan kegiatan yang paling pokok. Hussain, Azeem, \& Shakoor (2011) menjelaskan dalam penelitiannya bahwa hal terpenting dari proses pembelajaran adalah untuk mengoptimalkan kemampuan siswa dalam membuat keputusan terhadap berbagai situasi yang dihadapi. Siswa yang belajar akan mengalami perubahan baik dalam pengetahuan, keterampilan, nilai, dan sikap. Pengetahuan yang dipelajari di sekolah meliputi berbagai bidang disiplin ilmu, salah satunya adalah fisika.

Salah satu tujuan pembelajaran fisika menurut Permendiknas No. 22 tahun 2006 adalah mengembangkan kemampuan bernalar dalam berpikir analisis induktif dan deduktif dengan menggunakan konsep dan prinsip fisika untuk menjelaskan berbagai peristiwa alam dan menyelesaikan masalah baik secara kualitatif maupun kuantitatif. Adeyemo (2010) dalam penelitiannya menjelaskan bahwa fisika merupakan disiplin ilmu yang unik dan menarik. Fisika sulit untuk diajarkan dan dipahami. Fisika dapat dianggap sebagai HOT (higher order thinking). Hal ini merupakan tuntutan besar bagi siswa dalam proses pembelajaran. Lebih lanjut dijelaskan Hussain, Azeem, \& Shakoor (2011) bahwa kesulitan dalam proses pembelajaran siswa disebabkan pula oleh terbatasnya sumber, sarana, dan buku fisika terbaru. Permasalahan dalam pembelajaran ini dapat diminimalisir dengan memilih model 
dan metode pembelajaran yang tepat. Dengan demikian, dalam proses pembelajaran guru dituntut untuk dapat menciptakan pengalaman-pengalaman belajar melalui pemilihan model, pendekatan, metode, maupun strategi pembelajaran yang dapat memberikan kesempatan kepada siswa untuk berpartisipasi aktif dalam mengkonstruksi sendiri pengetahuannya dalam upaya pemecahan masalah fisika agar dapat tercapai tujuan pembelajaran fisika yang diharapkan.

Berdasarkan hasil observasi terhadap perangkat pembelajaran (RPP) dari guru mata pelajaran fisika SMAK St. Joanne Baptista Wolosambi, diketahui bahwa guru telah menerapkan pembelajaran kooperatif dalam perencanaan dan pelaksanaan pembelajaran di kelas. Model pembelajaran kooperatif merupakan kelompok strategi pembelajaran dalam usaha meningkatkan partisipasi siswa, memfasilitasi siswa dengan pengalaman sikap kepemimpinan dan membuat keputusan dalam kelompok, serta memberi kesempatan kepada siswa untuk berinteraksi dan belajar bersama-sama siswa yang berbeda latar belakangnya (Trianto, 2009: 58).

Slavin (2005) mengemukakan dua alasan pentingnya penerapan model pembelajaran kooperatif yaitu (1) Beberapa hasil penelitian membuktikan bahwa penggunaan pembelajaran kooperatif dapat meningkatkan prestasi belajar siswa sekaligus dapat meningkatkan kemampuan hubungan sosial, menumbuhkan sikap menerima kekurangan diri dan orang lain, serta dapat meningkatkan harga diri. (2) Pembelajaran kooperatif dapat merealisasikan kebutuhan siswa dalam belajar berpikir, memecahkan masalah, dan mengintegrasikan pengetahuan dengan keterampilan.

Merujuk pada proses pelaksanaan pembelajaran di kelas yang didasarkan pada hasil observasi dan wawancara dengan guru mata pelajaran, diperoleh informasi bahwa penerapan model pembelajaran ini belum dapat memberikan makna yang berarti bagi siswa. Pembelajaran dengan menggunakan sistem pengelompokkan yang sejatinya akan memunculkan tanggung jawab individu terhadap kelompok justru dijadikan sarana oleh sebagian siswa untuk melepaskan tanggung jawab kepada teman lain dalam kelompok. Keberhasilan kelompok tidak lagi menjadi tanggung jawab semua anggota kelompok, seperti yang diharapkan dalam pembelajaran ini.

Masalah ini secara jelas ditunjukkan dalam pencapaian prestasi akademik siswa. Oleh karena hanya sebagian anggota kelompok yang terlibat secara aktif dalam aktivitas belajar kelompok, maka hanya siswa tertentu yang memperoleh prestasi baik dan ironisnya siswa yang dimaksud ini adalah mereka yang memang memiliki kemampuan lebih dalam kelompok, sementara siswa yang berkemampuan kurang tetap memiliki masalah dengan prestasi mereka. Peran kelompok akhirnya menjadi tampak sia-sia sebab tidak dapat merealisasikan kebutuhan individu dalam belajar memecahkan masalah dan meningkatkan keterampilan interpersonal siswa.

Kenyataan di atas menunjukkan bahwa proses pembelajaran fisika belum berlangsung secara optimal sebab dalam suatu proses pembelajaran bukan saja proses penyampaian materi yang menjadi tuntutan namun juga bagaimana proses dengan siswa untuk menemukan apa yang dipelajari melalui berbagai macam kegiatan yang sesuai, sehingga sikap, pengetahuan, dan keterampilan dalam proses pembelajaran dapat lebih ditingkatkan.

Menyikapi permasalahan di atas, guru dituntut untuk mempersiapkan perencanaan pembelajaran sebagai acuan untuk melaksanakan dan mengevaluasi pembelajaran sesuai kebutuhan siswa serta perlu bijaksana dalam menentukan suatu model yang sesuai agar proses pembelajaran tidak hanya berpusat pada guru melainkan semua siswa dengan tingkat pengetahuan yang bervariasi dapat terlibat aktif guna mengembangkan kemampuan sikap, pengetahuan, dan keterampilannya. Salah satu cara untuk mengaktifkan siswa dalam mengembangkan ketiga kemampuan tersebut melalui penerapan model pembelajaran kooperatif.

Akan tetapi, apabila ditinjau lebih jauh dengan mempertimbangkan kenyataan yang sering terjadi di lapangan di mana dalam kegiatan kelompok, siswa cenderung untuk saling mengharapkan bantuan teman tetap menjadi kendala utama. Sifat alamiah untuk memperhatikan kebutuhan pribadi atau individu pun tetap menjadi hal yang harus diperhatikan secara khusus. Salah satu model pembelajaran kooperatif yang mengkombinasikan keunggulan kooperatif dan program pembelajaran individual adalah model pembelajaran kooperatif tipe TAI.

Model pembelajaran kooperatif tipe TAI dapat membantu siswa untuk mengukur kemampuannya sendiri serta terampil dalam berproses baik secara individu maupun kelompok. Dalam anggota kelompok itu sendiri tidak saling berkompetisi menjadi yang terbaik tetapi saling berbagi ilmu untuk mencapai pengetahuan bersama. Dalam pembelajaran kooperatif tipe TAI, para siswa saling mendukung dan saling membantu satu sama lain untuk berusaha keras karena mereka semua menginginkan tim mereka berhasil. Tanggung jawab individu dipastikan hadir karena satu-satunya skor yang diperhitungkan adalah skor akhir, dan siswa mengerjakan tes akhir tanpa bantuan teman satu tim. Menurut Slavin (2005), para siswa juga mendapat kesempatan sukses yang sama karena semuanya telah ditempatkan berdasarkan tingkat kemampuan atau pengetahuan yang dimiliki sebelumnya.

Sehubungan dengan proses pembelajaran fisika, hasil penelitian Warimun (2012) menunjukkan kebanyakan siswa dapat dengan mudah menerima pengetahuan tentang fisika, tetapi sukar mengaplikasikan pengetahuan secara fleksibel dalam memecahkan masalah. Oleh karena itu sangat penting bagi guru untuk berusaha menciptakan suasana belajar yang kondusif yang dapat mendukung siswa untuk terlibat aktif dalam menemukan sendiri masalah, menganalisisnya, dan memecahkan masalah berdasarkan konsep fisika yang telah dipelajari. 
Docktor \& Mestre (2014) menjelaskan salah satu alternatif pemecahan masalah dalam pembelajaran adalah real world problem. Kua, et al (2015) menjelaskan pula bahwa "Real world problems is one of the alternative solutions which in this case is used as away to introduce the students to the real problems in understanding the concept of physics". Pembelajaran berbasis pemecahan masalah dunia nyata mempunyai tujuan untuk mengembangkan dan menerapkan kecakapan yang penting yaitu pemecahan masalah nyata dalam lingkungan kehidupan siswa berdasarkan keterampilan belajar sendiri atau kerjasama kelompok dan memperoleh pengetahuan yang luas. Pada intinya pembelajaran berbasis pemecahan masalah merupakan suatu pembelajaran yang menggunakan masalah nyata untuk merangsang dan memudahkan siswa dalam mengasosiasikan permasalahan dengan konsep fisika yang dipelajari, kemudian masalah tersebut diselidiki untuk mendapatkan solusi yang tepat. Dengan demikian melalui penerapan model pembelajaran kooperatif tipe team asissted individualization dengan real world problem diharapkan dapat menjawab kebutuhan para guru dan siswa dalam memperoleh proses pembelajaran yang aktif dan berprestasi.

Pada penelitian ini akan dipaparkan hasil uji coba model pembelajaran kooperatif tipe team asissted individualization (TAI) dengan real world problem dalam pembelajaran fisika materi momentum dan impuls untuk mengetahui kepraktisan model pmbelajaran. Kepraktisan menunjukkan bahwa setiap fase dalam model pembelajaran kooperatif tipe TAI dengan real world problem dapat dilaksanakan dengan baik oleh guru model, sesuai dengan perangkat pendukung pembelajaran.

\section{Metode}

Penelitian ini merupakan pre-experimental design yang menggunakan one-shot case study sebab dalam penelitian ini hanya satu kelompok yang diberi perlakuan berupa penerapan model pembelajaran kooperatif tipe TAI dengan real world problem untuk kemudian diobservasi dan diketahui tingkat kepraktisan penerapan model pembelajaran. Populasi penelitian ini adalah seluruh siswa kelas X SMAK St. Joanne Baptista Wolosambi tahun ajaran 2017/2018 yang terbagi dalam dua kelas. Berdasarkan kriteria pengkategorian kemampuan awal kelompok menurut kaidah distribusi normal dengan menggunakan rerata nilai ujian fisika semester sebelumnya, diketahui bahwa populasi penelitian adalah homogen. Pengambilan sampel menggunakan teknik cluster random sampling, sehingga diperoleh X-B sebagai kelas yang diberi perlakuan (kelas eksperimen).

Model pembelajaran kooperatif tipe TAI dengan real world problem diterapkan dalam pembelajaran agar siswa dapat berproses baik secara individu maupun kelompok dalam meningkatkan kemampuan pemecahan masalah fisika. Untuk mengetahui kepraktisan model kooperatif tipe TAI dengan real world problem ini dilakukan dengan cara uji coba secara terbatas dalam pembelajaran fisika materi momentum dan impuls. Selain kepraktisan, dilakukan juga pengamatan terhadap keterampilan kooperatif siswa serta suasana kelas yang tercipta dalam proses. Pelaksanaan pembelajaran dilakukan oleh guru model dan diamati oleh observer.

Perlakuan subjek penelitian dilakukan dengan mengikuti langkah-langkah model pembelajaran kooperatif tipe TAI dengan real world problem seperti pada Tabel 1.

Tabel 1 Perlakukan subjek dengan Pembelajaran Kooperatif Tipe TAI dengan Real World Problem

\begin{tabular}{|c|c|c|}
\hline Fase & Tingkah Laku Guru & Tingkah Laku Siswa \\
\hline \begin{tabular}{l}
\multicolumn{1}{c}{ Fase 1} \\
Menyampaikan tujuan \\
dan memotivasi siswa
\end{tabular} & $\begin{array}{l}\text { Guru menyampaikan semua tujuan pelajaran } \\
\text { yang ingin dicapai pada pelajaran tersebut dan } \\
\text { memotivasi siswa. }\end{array}$ & $\begin{array}{l}\text { Siswa menyimak penyampaian tujuan } \\
\text { pembelajaran dari materi yang akan } \\
\text { dipelajari. }\end{array}$ \\
\hline $\begin{array}{c}\text { Fase } 2 \\
\text { Menyajikan informasi }\end{array}$ & $\begin{array}{l}\text { a. Guru menyajikan informasi kepada siswa } \\
\text { berupa gambar/video yang sesuai dengan } \\
\text { masalah nyata dalam kehidupan sehari-hari } \\
\text { siswa berdasarkan materi yang dipelajari. } \\
\text { b. Membimbing dan mengarahkan siswa untuk } \\
\text { mengidentifikasi masalah terkait konsep } \\
\text { fisika pada fenomena atau peristiwa yang } \\
\text { disajikan. } \\
\text { c. Menunjuk beberapa siswa untuk menyajikan } \\
\text { masalah yang telah diidentifikasi dan } \\
\text { penyelesainnya berdasarkan sudut pandang } \\
\text { dan pemahaman masing - masing siswa dari } \\
\text { fenomena yang telah diberikan. }\end{array}$ & $\begin{array}{l}\text { Siswa menyimak informasi yang } \\
\text { disajikan guru dan dapat memberikan } \\
\text { pertanyaan maupun pendapat atas } \\
\text { materi yang diberikan guru sesuai } \\
\text { pemahaman siswa berdasarkan } \\
\text { pengalaman nyata sehari-hari maupun } \\
\text { sumber pengetahuan lain. }\end{array}$ \\
\hline $\begin{array}{l}\text { Fase } 3 \\
\text { Mengorganisasikan } \\
\text { siswa ke dalam } \\
\text { kelompok-kelompok } \\
\text { belajar, terdiri dari: } \\
\text { Placement test, Teams } \\
\text { Teaching group }\end{array}$ & $\begin{array}{l}\text { Guru menjelaskan kepada siswa bagaimana } \\
\text { caranya membentuk kelompok belajar dan } \\
\text { membantu setiap kelompok agar melakukan } \\
\text { transisi secara efisien. }\end{array}$ & $\begin{array}{l}\text { Siswa mengerjakan pretest secara } \\
\text { individu untuk mendapatkan skor dasar } \\
\text { atau skor awal yang bertujuan untuk } \\
\text { menempatkan siswa pada kelompok } \\
\text { belajar yang heterogen didasarkan pada } \\
\text { hasil mereka. }\end{array}$ \\
\hline
\end{tabular}




\begin{tabular}{|c|c|c|}
\hline $\begin{array}{l}\text { Fase } 4 \\
\text { Membimbing kelompok } \\
\text { bekerja dan belajar, } \\
\text { terdiri dari: } \\
\text { Student creative } \\
\text { Team study }\end{array}$ & $\begin{array}{l}\text { Guru membimbing kelompok-kelompok } \\
\text { belajar pada saat menyelesaikan LKS berisi } \\
\text { masalah - masalah kontekstual terkait konsep } \\
\text { fisika yang dipelajari. Guru juga memberikan } \\
\text { bantuan secara individual bagi yang } \\
\text { memerlukannya.. }\end{array}$ & $\begin{array}{l}\text { Setiap kelompok mengerjakan tugas } \\
\text { dari guru berupa LKS. Pada tahap ini, } \\
\text { keberhasilan kelompok akan ditentukan } \\
\text { atau dipengaruhi oleh keberhasilan } \\
\text { individu sehingga sumbangan setiap } \\
\text { individu dalam kelompok sangat } \\
\text { penting. }\end{array}$ \\
\hline $\begin{array}{l}\text { Fase } 5 \\
\text { i, terdiri dari: } \\
t \\
\text { lass units }\end{array}$ & $\begin{array}{l}\text { si hasil belajar tentang materi } \\
\text { lajari atau masing-masing } \\
\text { resentasekan hasil kerjanya. } \\
\text { a memberikan tes secara }\end{array}$ & $\begin{array}{l}\text { Siswa mempresentasekan hasil diskusi } \\
\text { secara kelompok dan kemudian } \\
\text { mengerjakan tes secara individu yang } \\
\text { diberikan guru untuk mengukur } \\
\text { kemampuan siswa dalam memahami } \\
\text { materi yang diberikan }\end{array}$ \\
\hline $\begin{array}{l}\text { Fase } 6 \\
\text { Memberi pengha } \\
\text { Team score an }\end{array}$ & $\begin{array}{l}\text { encari cara-cara untuk menghargai baik } \\
\text { maupun hasil belajar individu dan } \\
\text { ok. }\end{array}$ & $\begin{array}{l}\text { menerima penghargaan } \\
\text { rja yang telah dilakukan } \\
\text { k. }\end{array}$ \\
\hline
\end{tabular}

(Sumber: Dimodifikasi dari Slavin, 2005: 101-104)

Sementara itu, keterampilan kooperatif peserta didik diperoleh dari hasil pengamatan yang dilakukan dalam interval ketika peserta didik sedangmelakukan kegiatan kelompok. Keterampilan kooperatif peserta didik dapat dihitung dengan menggunakan rumus:

$$
\% K K S=\frac{\sum K}{\sum f_{m}} \times 100 \%
$$

di mana

$\%$ KKS : Persentase ketrampilan kooperatif peserta didik

$\sum \mathrm{K} \quad$ : Jumlah tally (pemunculan ketrampilan kooperatif siswa dalam pembelajaran)

$\sum f_{\mathrm{m}} \quad$ : Frekuensi maksimal kegiatan inti pembelajaran.

Keterampilan kooperatif peserta didik dikatakan efektif jika 4 dari 5 aspek yang diamati pada tiap RPP berada pada kriteria batasan efektivitas.

Sebelum dilaksanakan uji coba pembelajaran menggunakan model kooperatif tipe TAI dengan real world problem, terlebih dahulu dilakukan persiapan, meliputi: 1) melakukan konsultasi kepada guru mata pelajaran fisika di sekolah tempat pelaksanaan penelitian untuk mengetahui jumlah populasi, kondisi kelas, jumlah guru, serta materi pokok yang akan diajarkan; 2) meminta guru model untuk mempelajari model pembelajaran kooperatif tipe TAI dengan real world problem beserta perangkat pembelajaran yang mendukung; 3) melakukan diskusi dengan guru model dan pengamat untuk mendapatkan pemahaman terkait model pembelajaran kooperatif tipe TAI dengan real world problem dan peran masing-masing dalam penelitian; (4) melakukan pemodelan pembelajaran kooperatif tipe TAI dengan real world problem untuk memberikan pengalaman secara langsung kepada guru model dan pengamat.

Selanjutnya, akan dilakukan uji coba. Pada tahap ini guru model akan melaksanakan proses pembelajaran fisika di kelas eksperimen menggunakan perangkat pembelajaran dengan model kooperatif tipe TAI dengan real world problem. Pada tahap ini pula, melalui bantuan 2 orang observer akan dilakukan observasi terhadap keterlaksanaan proses pembelajaran di kelas.

Untuk menganalisis hasil penilaian yang diberikan oleh pengamat terhadap kemampuan guru dalam mengelola pembelajaran melalui penerapan model pembelajaran kooperatif tipe TAI dengan real world problem digunakan ketentuan seperti pada Tabel 2.

Reliabilitas instrumen pengamatan dihitung dengan teknik Interobserver Agreement.

$$
R=1-\left(\frac{A-B}{A+B}\right) \times 100 \%
$$

dimana:

A : Frekuensi tertinggi pengamatan

B : Frekuensi terendah pengamatan

Instrumen pengelolaan pembelajaran dikatakan baik jika koofesien reliabilitas $\geq 75 \%$ (Suharsimi Arikunto, 2010). 
Tabel 2 Ukuran Kuantitatif Penilaian Kemampuan Guru

\begin{tabular}{|c|c|c|}
\hline $1,00 \leq P<1,75$ & Tidak Baik & $\begin{array}{l}\text { Jika guru tidak mampu mengelola kegiatan } \\
\text { pembelajaran menggunakan model kooperatif tipe } \\
\text { team assisted individualization dengan real world } \\
\text { problem. }\end{array}$ \\
\hline $1,75 \leq P<2,50$ & Kurang Baik & $\begin{array}{l}\text { Jika guru kurang mampu mengelola kegiatan } \\
\text { pembelajaran menggunakan model kooperatif tipe } \\
\text { team assisted individualization dengan real world } \\
\text { problem. }\end{array}$ \\
\hline $2,50 \leq P<3,25$ & Cukup Baik & $\begin{array}{l}\text { Jika guru cukup mampu mengelola kegiatan } \\
\text { pembelajaran menggunakan model kooperatif tipe } \\
\text { team assisted individualization dengan real world } \\
\text { problem. }\end{array}$ \\
\hline $3,25 \leq P<4,00$ & Sangat Baik & $\begin{array}{l}\text { Jika guru sangat mampu mengelola kegiatan } \\
\text { pembelajaran menggunakan model kooperatif tipe } \\
\text { team assisted individualization dengan real world } \\
\text { problem. }\end{array}$ \\
\hline
\end{tabular}

\section{Hasil dan Pembahasan}

Sumber: Dimodifikasi dari Borich (Arikunto, 2010: 3-4)

Pelaksanaan penelitian berupa kegiatan pembelajaran yang dilakukan oleh guru model di kelas X-B SMAK St. Joanne Baptista Wolosambi. Perangkat pembelajaran yang digunakan dalam proses pembelajaran terdiri dari silabus, RPP, LKS, lembar pengamatan keterampilan kooperatif siswa, dan lembar isian suasana kelas pada proses pembelajaran. Sebelum perangkat pembelajaran dengan materi pokok momentum dan impuls diterapkan dalam proses pembelajaran, perangkat tersebut divalidasi oleh dosen ahli materi dan praktisi. Hasil validasi diberikan pada Tabel 3.

Tabel 3 Hasil Validasi

\begin{tabular}{|c|c|c|c|c|c|c|}
\hline \multirow[t]{2}{*}{ No } & \multirow[b]{2}{*}{$\begin{array}{l}\text { Perangkat } \\
\text { yang } \\
\text { divalidasi }\end{array}$} & \multicolumn{3}{|c|}{ Hasil Validasi } & \multirow[b]{2}{*}{ RTV } & \multirow[b]{2}{*}{ Keterangan } \\
\hline & & Validator 1 & Validator 2 & Validator 3 & & \\
\hline 1 & $\begin{array}{c}\text { Rencana } \\
\text { pelaksanaan } \\
\text { pembelajaran }\end{array}$ & 4,40 & 3,98 & 4,58 & 4,32 & $\begin{array}{l}\text { RPP ini berada pada } \\
\text { kategori sangat baik dan } \\
\text { dapat digunakan dengan } \\
\text { revisi kecil. }\end{array}$ \\
\hline 2 & $\begin{array}{c}\text { Lembar kerja } \\
\text { siswa }\end{array}$ & 4,60 & 4,50 & 4,17 & 4,42 & $\begin{array}{l}\text { LKS ini berada pada } \\
\text { kategori sangat baik dan } \\
\text { dapat digunakan dengan } \\
\text { revisi kecil. }\end{array}$ \\
\hline
\end{tabular}

Berdasarkan RTV (rata-rata total validasi) pada Tabel 3, disimpulkan bahwa masing-masing perangkat yaitu RPP dan LKS berada pada kategori sangat baik dengan adanya beberapa revisi kecil untuk diperbaiki sebelum perangkat digunakan dalam proses pembelajaran.

Selanjutnya, uji coba dilakukan oleh guru model. Guru model melaksanakan proses pembelajaran fisika menggunakan model kooperatif tipe TAI dengan real world problem disertai perangkat pendukung yang telah divalidasi dan media pembelajaran yang sesuai dengan masalah nyata dalam kehidupan sehari - hari siswa.

Penilaian terhadap proses pembelajaran yang terjadi serta suasana kelas yang tercipta dalam pembelajaran menggunakan model kooperatif tipe TAI dengan real world problem dilakukan oleh dua orang observer. Kepraktisan model pembelajaran kooperatif tipe TAI dengan real world problem saat pelaksanaan pembelajaran ditampilkan pada Tabel 4.

Tabel 4 menunjukkan bahwa model pembelajaran kooperatif tipe TAI dengan real world problem secara umum praktis diterapkan dalam pembelajaran fisika. Guru model dapat menerapkan setiap fase model pembelajaran ini dengan sangat baik. Hasil pengamatan memiliki koefesien reliabilitas di atas $75 \%$, sehingga memiliki kategori reliabel.

Tabel 4 Kepraktisan Model Pembelajaran Kooperatif Tipe TAI dengan Real World Problem

\begin{tabular}{|c|c|c|c|c|c|c|c|}
\hline \multirow{2}{*}{ Fase Model pembelajaran } & \multicolumn{7}{|c|}{ Pembelajaran dengan Materi Momentum dan Impuls } \\
\hline & Pertemuan 1 & Pertemuan 2 & Pertemuan 3 & $\mathrm{~K}$ & Ket & $\% \mathrm{R}$ & Ket \\
\hline $\begin{array}{l}\text { Menyampaikan tujuan dan } \\
\text { memotivasi siswa }\end{array}$ & 3,50 & 3,25 & 3,75 & 3,50 & SB & 85,71 & $\mathrm{R}$ \\
\hline
\end{tabular}




\begin{tabular}{|c|c|c|c|c|c|c|c|}
\hline $\begin{array}{l}\text { Menyajikan informasi berbasis } \\
\text { real world problem. }\end{array}$ & 3,60 & 3,50 & 3,75 & 3,61 & SB & 85,71 & $\mathrm{R}$ \\
\hline $\begin{array}{l}\text { Mengorganisasikan siswa ke } \\
\text { dalam kelompok-kelompok } \\
\text { belajar, terdiri dari: } \\
\text { Placement test } \\
\text { Teams } \\
\text { Teaching group }\end{array}$ & 3,25 & 3,75 & 3,50 & 3,50 & SB & 100 & $\mathrm{R}$ \\
\hline $\begin{array}{l}\text { Membimbing kelompok bekerja } \\
\text { dan belajar menggunakan real } \\
\text { world problem sebagai alternatif } \\
\text { pemecahan masalah, terdiri dari: } \\
\text { Student creative } \\
\text { Team study }\end{array}$ & 4,00 & 4,00 & 4,00 & 4,00 & SB & 100 & $\mathrm{R}$ \\
\hline $\begin{array}{l}\text { Evaluasi, terdiri dari: } \\
\text { Fact test } \\
\text { Whole-class units }\end{array}$ & 3,50 & 3,25 & 3,75 & 3,50 & SB & 85,71 & $\mathrm{R}$ \\
\hline $\begin{array}{l}\text { Memberi penghargaan } \\
\text { Team score and team } \\
\text { recognition }\end{array}$ & 3,68 & 3,83 & 3,76 & 3,75 & SB & 85,71 & $\mathrm{R}$ \\
\hline
\end{tabular}

Keterangan: $\mathrm{K}=$ Kepraktisan, $\mathrm{R}=$ Reliabilitas, $\mathrm{SB}=$ Sangat Baik

Keterampilan kooperatif siswa merupakan kemampuan siswa untuk mengoperasikan kerja dan tugas dalam kelompok secara mudah dan cermat dengan mengembangkan kemampuan dasar yang dimiliki untuk merealisasikan kebutuhan kelompok dalam memecahkan masalah bersama. Penilaian keterampilan kooperatif yang diperoleh dari hasil pengamatan yang dilakukan dalam interval ketika siswa sedang melakukan kegiatan kelompok didasarkan pada instrumen pengamatan keterampilan kooperatif siswa. Analisis hasil penagamatan terhadap keterampilan kooperatif siswa dapat dilihat pada Tabel 5 di bawah ini.

Berdasarkan Tabel 5 diketahui bahwa keterampilan kooperatif siswa mengalami peningkatan dari pelaksanaan RPP 01-03. Keterampilan kooperatif siswa secara umum dikatakan efektif jika 4 dari 5 aspek yang diamati berada pada kriteria batasan efektivitas.

Tabel 5 Hasil Analisis Keterampilan Kooperatif Siswa

\begin{tabular}{|c|c|c|c|c|c|}
\hline \multirow[t]{2}{*}{ No } & \multirow[t]{2}{*}{ Aspek yang Diamati } & \multicolumn{3}{|c|}{$\begin{array}{c}\text { Persentase Keterampilan Kooperatif } \\
\text { Siswa (\%) }\end{array}$} & \multirow{2}{*}{$\begin{array}{c}\text { Kriteria } \\
\text { Toleransi } \\
\text { Batasan } \\
\text { Efektifvitas (\%) }\end{array}$} \\
\hline & & $\begin{array}{l}\text { Pertemuan } \\
1\end{array}$ & $\begin{array}{l}\text { Pertemuan } \\
\quad 2\end{array}$ & Pertemuan 3 & \\
\hline 1. & Berada dalam tugas & 95.33 & 96.67 & 97.67 & $95-100$ \\
\hline 2. & $\begin{array}{l}\text { Mengambil giliran dan } \\
\text { berbagi tugas }\end{array}$ & 33.67 & 34.67 & 36.33 & $35-45$ \\
\hline 3. & Mendorong berpartisipasi & 14.33 & 18.33 & 18.00 & $15-25$ \\
\hline 4. & Bertanya atau menjawab & 25.33 & 27.67 & 29.67 & $20-30$ \\
\hline 5. & $\begin{array}{l}\text { Mendengarkan dengan } \\
\text { aktif }\end{array}$ & 16.33 & 18.00 & 18.67 & $10-20$ \\
\hline
\end{tabular}

Suasana kelas yang tercipta pada pembelajaran dengan model kooperatif tipe TAI dengan real world problem disajikan pada Tabel 6.

Tabel 6 menunjukkan bahwa dalam penerapan model pembelajaran kooperatif tipe TAI dengan real world problem guru dapat mengelola setiap fase dengan baik sehingga menciptakan suasana pembelajaran yang mendukung para siswa memahami materi fisika yang diberikan. Pembelajaran dengan model ini memberikan fokus perhatian pada siswa dan menuntut peran guru dalam memberikan inspirasi agar potensi dan kemampuan siswa dimaksimalkan sehingga seluruh rangkaian kegiatan pembelajaran mencapai tujuan yang diharapkan. Pemberian materi yang didasarkan pada pengalaman nyata siswa dalam kehidupan sehari - hari memudahkan siswa dalam mengasosiasikan permasalahan dengan konsep fisika yang dipelajari, kemudian masalah tersebut 
diselidiki untuk mendapatkan solusi yang tepat. Hasil pengamatan memiliki koefesien relibilitas di atas $75 \%$ sehingga termasuk dalam kategori reliabel.

Tabel 6 Suasana Kelas dalam Proses Pembelajaran Model Kooperatif Tipe TAI dengan Real World Problem

\begin{tabular}{|c|c|c|c|c|c|c|c|}
\hline \multirow[b]{2}{*}{$\begin{array}{c}\text { Suasana kelas dalam proses } \\
\text { pembelajaran }\end{array}$} & \multicolumn{7}{|c|}{ Pembelajaran dengan Materi Momentum dan Impuls } \\
\hline & $\begin{array}{c}\text { Pertemuan } \\
1\end{array}$ & $\begin{array}{l}\text { Pertemuan } \\
\quad 2\end{array}$ & $\begin{array}{l}\text { Pertemuan } \\
3\end{array}$ & $\mathrm{~K}$ & Ket & $\% \mathrm{R}$ & Ket \\
\hline $\begin{array}{l}\text { Kesesuaian seluruh rangkaian kegiatan } \\
\text { pembelajaran dengan tujuan pembelajaran. }\end{array}$ & 4,00 & 3,50 & 3,50 & 3,67 & SB & 85,71 & $\mathrm{R}$ \\
\hline $\begin{array}{l}\text { Penggunaan media pembelajaran yang } \\
\text { kontekstual dan mendukung siswa dalam } \\
\text { memahami materi yang disajikan. }\end{array}$ & 3,50 & 3,50 & 4,00 & 3,67 & SB & 85,71 & $\mathrm{R}$ \\
\hline $\begin{array}{l}\text { Pemberian contoh - contoh yang sesuai } \\
\text { dengan fenomena dalam kehidupan sehari - } \\
\text { hari siswa. }\end{array}$ & 4,00 & 4,00 & 4,00 & 4,00 & SB & 100 & $\mathrm{R}$ \\
\hline $\begin{array}{l}\text { Pemberian materi dengan gaya bahasa yang } \\
\text { mudah dipahami siswa }\end{array}$ & 4,00 & 3,50 & 3,50 & 3,67 & $\mathrm{SB}$ & 85,71 & $\mathrm{R}$ \\
\hline $\begin{array}{llll}\text { Pembelajaran membantu } & \text { siswa } & \text { secara } \\
\text { individu maupun kelompok } & & \\
\end{array}$ & 3,50 & 3,50 & 3,50 & 3,50 & SB & 85,71 & $\mathrm{R}$ \\
\hline $\begin{array}{l}\begin{array}{l}\text { Kreativitas guru dalam } \\
\text { pembelajaran. }\end{array} \\
\text { pengelola } \\
\end{array}$ & 3,50 & 3,50 & 3,50 & 3,50 & $\mathrm{SB}$ & 85,71 & $\mathrm{R}$ \\
\hline $\begin{array}{llll}\text { Antusiasme } & \text { guru } & \text { dalam } & \text { proses } \\
\text { pembelajaran. } & & & \end{array}$ & 4,00 & 4,00 & 4,00 & 4,00 & SB & 100 & $\mathrm{R}$ \\
\hline $\begin{array}{llll}\begin{array}{l}\text { Antusiasme } \\
\text { pembelajaran }\end{array} & \text { siswa } & \text { dalam } & \text { proses } \\
\end{array}$ & 3,50 & 3,50 & 4,00 & 3,67 & SB & 85,71 & $\mathrm{R}$ \\
\hline Interaksi antara guru dengan siswa & 3,50 & 4,00 & 3,50 & 3,67 & SB & 85,71 & $\mathrm{R}$ \\
\hline Interaksi antar siswa & 3,50 & 3,50 & 3,50 & 3,50 & SB & 85,71 & $\mathrm{R}$ \\
\hline
\end{tabular}

Keterangan: $\mathrm{K}=$ Kepraktisan, $\mathrm{R}=$ Reliabilitas, $\mathrm{SB}=$ Sangat Baik

Model pembelajaran dikatakan praktis jika model pembelajaran tersebut dapat diterapkan di lapangan dengan tingkat keterlaksanaan termasuk dalam kategori baik. Bertolak dari hasil penelitian Nieveen (1999) yang mengungkapkan bahwa kepraktisan model pembelajaran ditunjukkan melalui kemudahannya ketika diterapkan dalam proses pembelajaran. Hasil penelitian di atas menunjukkan bahwa fase - fase dalam model pembelajaran kooperatif tipe TAI dengan real world problem praktis diterapkan guru dalam pembelajaran fisika.

\section{Simpulan}

Model pembelajaran kooperatif tipe TAI dengan 6 langkah pembelajaran yang dipadukan dengan menggunakan alternatif pemecahan masalah real world problem berdasarkan hasil penelitian memiliki tingkat kepraktisan yang sangat baik dengan nilai reliabilitas di atas $75 \%$. Hal ini menunjukkan bahwa model pembelajaran ini praktis untuk diterapkan guru dalam proses pembelajaran. Keterampilan kooperatif siswa secara umum adalah efektif dengan persentase rata-rata masing-masing aspek berada pada kriteria toleransi batasan efektivitas. Suasana kelas yang tercipta ketika guru menerapkan model pembelajaran ini termasuk dalam kategori sangat baik dengan nilai reliabilitas di atas $75 \%$. Dengan demikian, model pembelajaran kooperatif tipe TAI dengan real world problem sangat baik dan efektif diterapkan guru dalam pembelajaran karena dapat memberikan kesempatan kepada siswa untuk membangun sendiri pemahaman konsep fisika berdasarkan pengalaman nyata dalam kehidupan sehari-hari).

\section{Daftar Rujukan}

Adeyemo, S. A. (2010). Background and Classroom Corelates of Students' Achievement in Physics, International Journal of Educational Research and Technology, 1, 25-34.

Depdiknas. (2006). Peraturan Pemerintah RI Nomor 22, Tahun 2006, tentang Standar Isi.

Docktor, J. L., \& Mestre, J. P. (2014). Synthesis of Discipline-Based Education Research in Physics. Physical Review Special Topics-Physics Education Research, 10, 1-58.

Hussain, A., Azeem, M., \& Shakoor, A. (2011). Physics Teaching Methods: Scientific Inquiry Vs Traditional Lecture. International Journal of Humanities and Social Science, 1 (19), 269-276.

Kua, M.Y., Ulviah, L., Sawu, A.M., \& Ngole,M. (2015). Analysis of the Speed of a Moving Object through the Application of Videopad to Teach Mechanical Concepts Based on a Real World Problem. Proceeding International Seminar on Scienxe Education - Harmonization of Science, Technology, and society (STS) 
in science Learning to Prepare $21^{\text {st }}$ Century Generation (255-266). Yogyakarta: Universitas Negeri Yogyakarta.

Slavin, R. E. (2005). Cooperative Learning, Second Edition. Massachusets: Allyn \& Bacon.

Trianto. (2009). Mendesain Model Pembelajaran Inovatif Progresif Konsep, Landasan dan Implementinya Pada KTSP. Jakarta: Kencana Prenata Media.

Warimun, E. (2012). Penerapan Model Pembelajaran Problem Solving Fisika pada Pembelajaran Topik Optika pada Mahasiswa Pendidikan Fisika. Jurnal Exacta, 10, 111-114. 